\title{
Comprehensive Control of Horizontal Well of Deep Profile Technology Research
}

\author{
Yong Wang, Yanrong Chang, Hongjun Lu, Suiwang Zhang, Xiaobin Lu, Xiaoli Shen \\ Oil \& Gas Technology Research Institute Changqing Oilfield Company; National Engineering Laboratory for Low \\ Peemeability Petroleum Exploration and Development, Xian,710021,Shanxi,China
}

\begin{abstract}
With the gradual deepening of Changqing Oilfield horizontal wells, horizontal wells see water phenomenon is gradually increasing, more than $80 \%$ of the current water level of high water wells horizontal wells accounted for $25.5 \%$ of the total number of open wells. High water level of wells governance means there are horizontal wells to find the mechanical plugging wells, corresponding water depth profile control, bi-directional oil wells plugging technology, by contrast, the current techniques of horizontal wells in Changqing Oilfield high water governance best suited for the corresponding injection wells be deep profile. By reason of the horizontal well see the water, see water type analysis, and ultimately optimize the construction program, citing CDST-01 blocking agent system and application of multi-level multi-round profile control technology to achieve effective governance of the high water level of wells. Field test seven wells, increasing the average single-well oil 4.5t, average moisture content decreased $68 \%$, cumulative oil $3825 t$, cumulative precipitation $4585 \mathrm{~m} 3$, a significant treatment effect, provide a reference for the next step Changqing Oilfield high water level governance and reference wells .
\end{abstract}

Keywords-High water horizontal wells, Corresponding injection wells, Deep profile, Multi-level multi-round

\section{INTRODUCTION}

With the gradual deepening of horizontal wells in Changqing Oilfield, Changqing Oilfield high water gradually increased horizontal wells, horizontal wells due to the construction of large investment, well productivity, high water problem has seriously affected the horizontal well development. Currently used as a means of governance machinery to find plugging wells, corresponding water depth profile control, bi-plugging oil wells three techniques. However, due to the artificial fracture horizontal wells, could easily lead to both horizontal and vertical Unicom, water channeling the direction of the complex, resulting in mechanical plugging technology success rate, and higher costs; injection wells corresponding profile of the construction process is not only simple and Construction cycle is short, well quick, low operating costs, so the corresponding injection wells deep profile control is an effective way to control high water levels are currently well. But in the actual construction process compared with conventional directional drilling, there are still difficulties in two aspects: First, because of the large drain horizontal wells pumping intensity, the corresponding profile in injection wells along the cracks when plugging agent breakthrough speed, blocking agent in minor gum when already a breakthrough, causing plugging failure; two horizontal wells due to the artificial fractures, blocking agent injection process will crack along different onrush, causing loss of blocking agent into account, so that the concentration of blocking agent, gelling strength weakened, reducing its closure blocking resistance.

\section{TECHNICAL IMPROVEMENTS}

In order to solve the current high water injection wells horizontal wells corresponding profile problems in the process, the process has been improved cross reversed in three areas: the construction process optimization, CDST-01 blocking agent system and application of multi-level multi-round profile technology.

\section{A. Optimization of Construction Technology}

For large horizontal wells pumping intensity, the corresponding profile in injection wells along the cracks when plugging agent breakthrough speed, blocking agent in the rubber already unsuccessfully to break, resulting in the failure of the status block, through technical research, carried out the "two optimization "to ensure that the large pumping intensity, blocking agent" to retain, to a plastic, high strength ", effectively sealing the cracks.

(1) Optimize the leading edge of the slug strength. To ensure the blocking agent can retain in fractures, carried profile construction, the need to further improve the gelling strength. By optimizing the leading edge of the slug from weak to strong gel optimized gel blocking agent concentration from $0.3 \%$ to $1.0 \%$ adjustment; particle size used by the $1 \mathrm{~mm}-2 \mathrm{~mm}$ adjusted $3 \mathrm{~mm}-4 \mathrm{~mm}$, ensure blocking agent can fracture stay.

(2) Optimize the construction emissions. To ensure that in the larger pumping intensity, the leading edge of the slug into a gel and can be able to make a follow-up slug gel strength gradually increased, the current construction of displacement by the $3-5 \mathrm{~m}^{3} / \mathrm{h}$ optimized for $2-8 \mathrm{~m}^{3} / \mathrm{h}$, that is when the leading edge of the slug during implantation, increased construction displacement, shortening the blocking agent into the gel time; reduce emissions in the subsequent construction slug injection process to ensure that the blocking agent intensity gradually increased. 


\section{B. Application CDST-01 blocking agent system}

Existing profile system is basically solved the horizontal injection wells in water shutoff profile was maintained into and blocking issues, but there effectiveness is poor, the problem of short validity period for this situation for blocking agent system for the exploration and research, development slow expansion of the CDST-01-type profile system which gel particles to improve absorption capacity compared to the conventional system of nearly 20 times as adhesive degrees up $175000 \mathrm{mPa} . \mathrm{s}$, can adapt to different $\mathrm{PH}$, different salinity formation, resistance erosion, safety, environmental pollution, lower drug costs and other characteristics.

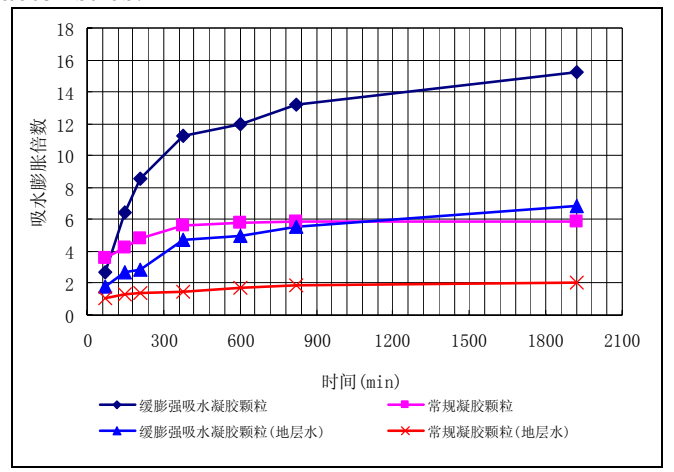

Figure 1. Swelling properties of the gel particles results

\section{Application of multi-level multi-round profile technology}

For artificial fracture horizontal wells, multi-directional see the water problem, launched the "Well see multi-level multi round profile multi-directional technology research", see the time on the difference between the water and the different permeability ratio according to flooded wells, determine the a multi-level multi-round closure theory, under the same premise of the total blocking agent, through the "single-round low-dose, multi-round focus" into ways to shorten the reaction time of different blocking agents, and to increase the amount of gelling adhesive strength, reduce blocking agent into account the loss in different fracture.

Through laboratory tests, multi-level multi-round block was verified, as shown in Figure 2: water flooding during sudden injection of water along the cracks, not oily areas of effective displacement (process(1)), adjusted by round after a cross-sectional (process (2)), then when the water flooding, due to a certain degree of crack closure, injecting water to displace oil region, but due to the crack closure is not complete, there are still some cracks along the injected water onrush (process (3)); their profile after the second round (process (4)), then when the water flooding, the ability to further improve sealing cracks, water can not be injected through the cracks, instead displacing oil region (process (5)); multilevel multiple rounds plugging rate than single-round profile by nearly $25 \%$.

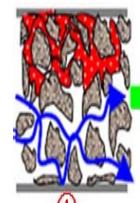

(1)

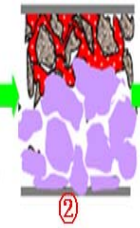

(2)
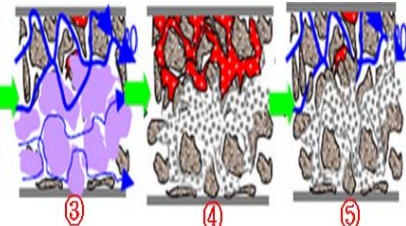

Figure 2 Multi-level multi-round profile block schematic

\section{IMPLEMENTATION EFFECT}

By improving the technology and application of three, in 2013 a total of Changqing Oilfield demonstration area seven horizontal wells horizontal wells corresponding high water injection wells were deep profile construction, measures the average single well after increasing oil 5.0t, average moisture down 60\%, cumulative oil 3825t, cumulative rainfall $4585 \mathrm{~m}^{3}$; area 7 after conventional directional wells profile, increasing the average single-well oil 1.9t, average moisture content decreased by $11.8 \%$,cumulative oil $1402 \mathrm{t}$, cumulative precipitation $2658 \mathrm{~m}^{3}$; from compared to effect, horizontal wells corresponding water depth profile control treatment effect more pronounced.

\section{CONCLUSIONS AND RECOMMENDATIONS}

(1) Through the high water injection wells corresponding horizontal wells deep profile control is an effective means of high water levels to govern well,more conventional directional wells significantly better than profile.

(2) Optimization of targeted programs, CDST-01 blocking agent system and multi-level multi-round application of technology, to solve the high water level of the well water depth profile control corresponding technical problems have a good effect, with water of high Hirai governance provides a useful reference.

(3) At present in the horizontal well corresponding to choose a well of water injection profile, commonly used method for the dynamic monitoring method, suggest the IPI of directional well are commonly used by the decision of selecting well technical reference to the corresponding horizontal well water injection profile, and combined with horizontal well special conditions and the regularity of water breakthrough, fracture type, form a new technology of horizontal well decision to choose corresponding injectors.

\section{REFERENCES}

[1] Yan Shu Yun,Wang Jian,Bai yuan. Low permeability oil field water depth profile control technology improvement and promotion [J]. Liaoning Chemical Industry, 2011,9 (40),962-965

[2] Jiang Han Qiao. Multiple round profile numerical simulation study [J]. Oil Drilling \& Production Technology, 2003,25 (5),63-67

[3] He Qiuxuan, Ruan Min, Wang Zhiwei. Production characteristics and influencing factors of the development of low permeability reservoirs [J]. Petroleum Geology and Recovery Efficiency, 2002,9 (2) :6-9

[4] Jia Xiaofei, Lei Guanglun, Gu Xiaoyu. Water depth profile control technology research status and development trend [J]. Specialty reservoir, 2009,4 (16),6-12 